\title{
Solvent Extraction And Spectrophotomteric Determination Of Cu(Ii) With Dicyclohexyl - 18- Crown-6
}

\author{
Suad Salman Muhammad* \\ Received 25, September, 2012 \\ Accepted 9, December, 2012
}

\begin{abstract}
:
Liquid-Liquid Extraction of $\mathrm{Cu}(\mathrm{II})$ ion in aqueous solution by dicyclohexyl-18crown-6 as extractant in dichloroethane was studied .The extraction efficiency was investigated by a spectrophometric method.

The reagent form a coloured complex which has been a quantitatively extracted at $\mathrm{pH}$ 6.3. The method obeys Beer's law over range from $(2.5-22.5) \mathrm{ppm}$ with the correlation coefficient of 0.9989 . The molar absorptivity $1 \times 10^{4} \mathrm{~L} \mathrm{~mol}^{-1} \mathrm{~cm}^{-1}$ the stoichiometry of extracted complex is found to be $1: 2$. the proposed method is very sensitive and selective.
\end{abstract}

Key words: dicyclohexy l- 18 - crown - 6, copperd etermination , Extraction Spectrophotometry.

\section{Introduction:}

Copper has many applications and its separation and estimation at trace level is of considerable importance. For determination of copper, various methods, Including atomic absorption spectropotometry ,ion chromatography, anodic striping analysis ,inductively coupled plasma mass spectrometry have been used $^{(1,2,3)}$.Many of these methods are either time consuming or require complicated and expensive instruments. Determination by solvent extraction is fast and simple process .This method is based on differences in solubilities of element and their compounds in two immiscible liquid media.

The method is usually used to remove metals from an aqueous solution .This requires organic solvent immiscible with water and appropriate ligands or complexing agent to form metal complexes .Copper is one of the most important metals after iron. It is used in many fields either as metal or its salts

such as industry, laboratory medicine, food, and beverage ${ }^{(1)}$. Copper and its salts are highly toxic to lower organisms much more than man; however, it is an essential constituent of certain proteins ${ }^{(4)}$. Its toxic effect is main cause of Wilson`s disease ${ }^{(5)}$. the In plant physiology it is essential as a component of number of different plant enzymes ${ }^{(6)}$.It is one of the most harmful impurities in semiconductor materials ${ }^{(7)}$ several compounds are known to react with metal ions to give coloured complexes and have been employed for the quantitative extraction and spectrophotometric determination of metal at trace levels ${ }^{(8,9,10,11)}$ but no work seems to have been done using dicyclohexyl-18-crown- 6 (DCH-18Crown-6). Therefore, it was thought of interest to develop suitable method for the determination of copper(II) with above reagent .The use of this reagent may prove to be advantageous . In the present paper, the extraction and

*Department of Chemistry, College of Science for women, University of Baghdad, 
spectrophotometric determination of copper (II) with dicyclohexyl-18crown- 6 (DCH-18-Crown-6) is proposed, which found to be simple, sensitive, rapid and precise.

\section{Materals and Methods}

All chemical reagents and solvent are standard analytical grade purchased from BDH. The stock solution of copper (II) $\mathrm{mg} \mathrm{ml}^{-1}$ is prepared by dissolving a $3.928 \mathrm{~g}$ of its sulphat penta hydrate in double distilled water containing $1 \mathrm{ml}$ concentrated sulphuric acid. Solution is diluted to the desired concentration with double distilled water as required, $\left(10^{-3} \mathrm{M}\right)$ of the solution of extractants are prepared by dissolving appropriate (dicyclohexyl -18- crown 6 ) in dichloroethane which was diluted to the desired concentration with dichloroethane.

Ammonia,dilute solution is used ( 1 drop of concentrated ammonia in 20 $\mathrm{ml}$ of double distilled water). The absorbance is measured by shimadzu uv-visible (160) spectrophotometer with $1 \mathrm{~cm}$ quartz cells. $\mathrm{pH}$ of aqueous phase is measured with $\mathrm{pH}$ meter, $\mathrm{pw}$ 9421, ( phlilips England ).

All the solutions are freshly prepared daily.

Extraction Method

To $2.0 \mathrm{ml}$ of aqueous solution containing $20 \mu \mathrm{g}$ of metal ion solution in a $10 \mathrm{ml}$ glass-stoppered tube .The $\mathrm{pH}$ is adjusted to 6.3 then $4 \mathrm{ml}$ of (dicyclohexyl- 18- crown-6) as extractant in 1,2 dichloroethane solution is added and mixture is shaken mechanically at room temperature for $10 \mathrm{~min}$. and allowed to separate. The metal ion concentration in aqueous phase is determined. The (Brownish-pale) coloured orqanic phase is separated and dried over silica gel to remove trace of water.

The absorbance of organic phase containing the complex is measured at $(469 \mathrm{~nm})$ against a reagent blank.

\section{Result and Discussion:}

The reagent dicylohexyl- 18crown-6 form (Brownish-pale) coloured complex with $\mathrm{Cu}(\mathrm{II})$, which is extracted into organic phase.

The extraction of $\mathrm{Cu}$ (II)is studied over a wide range of experimental conditions .The results of various studies are discussed below.

\section{Absorption spectrum}

The absorption spectrum of $\mathrm{Cu}$ (II) dicyclo hexyl -18-crown-6 in dichoroethane (Fig 1 ) shows the maximum absorption at (469) $\mathrm{nm}$ the absorption due to reagent at this wave length is nearly negligible. Hence Extraction of copper (II) dicyclohexyl18-crown-6-carried out at (469) $\mathrm{nm}$ all the 


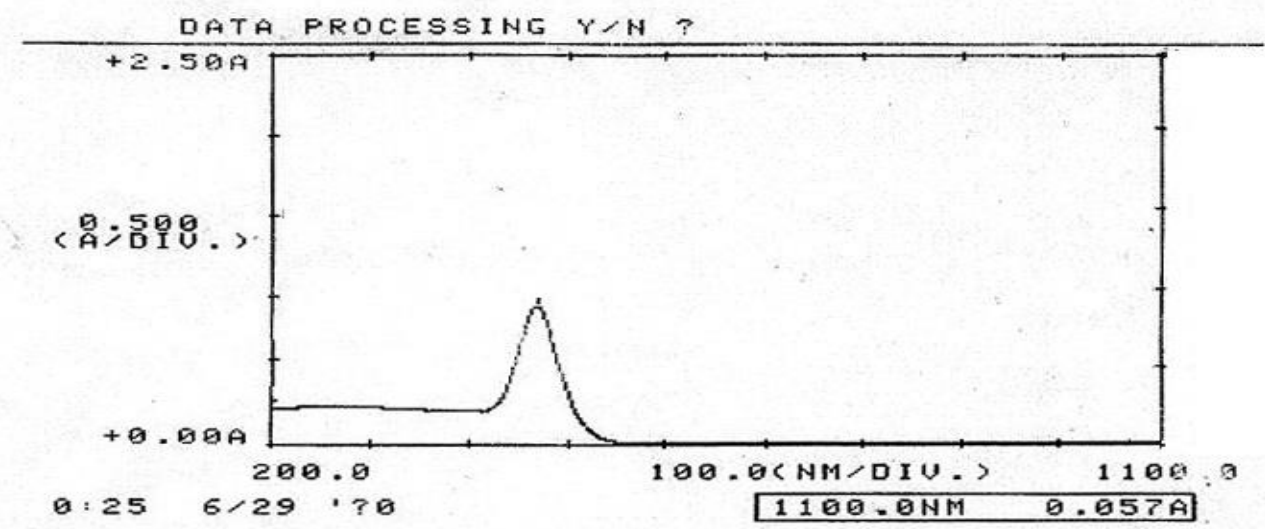

Fig(1) Absorption spectra Cu(II)DCH-18-crown-6

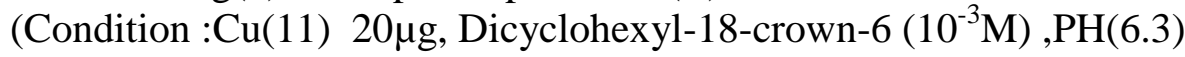

Influence of
efficienciy

Six different $\mathrm{pH}$ solutions ranging from $\mathrm{pH}(4-9)$ are prepared for the extracting of $\mathrm{Cu}(\mathrm{II})$ - dicyclohexyl- 18-crown-6 into dichloroethane.the percentage extraction of complex depends on the $\mathrm{pH}$ of solution as shown in(Fig2).Hence all extraction of copper is carried at (6.3) $\mathrm{pH}$.

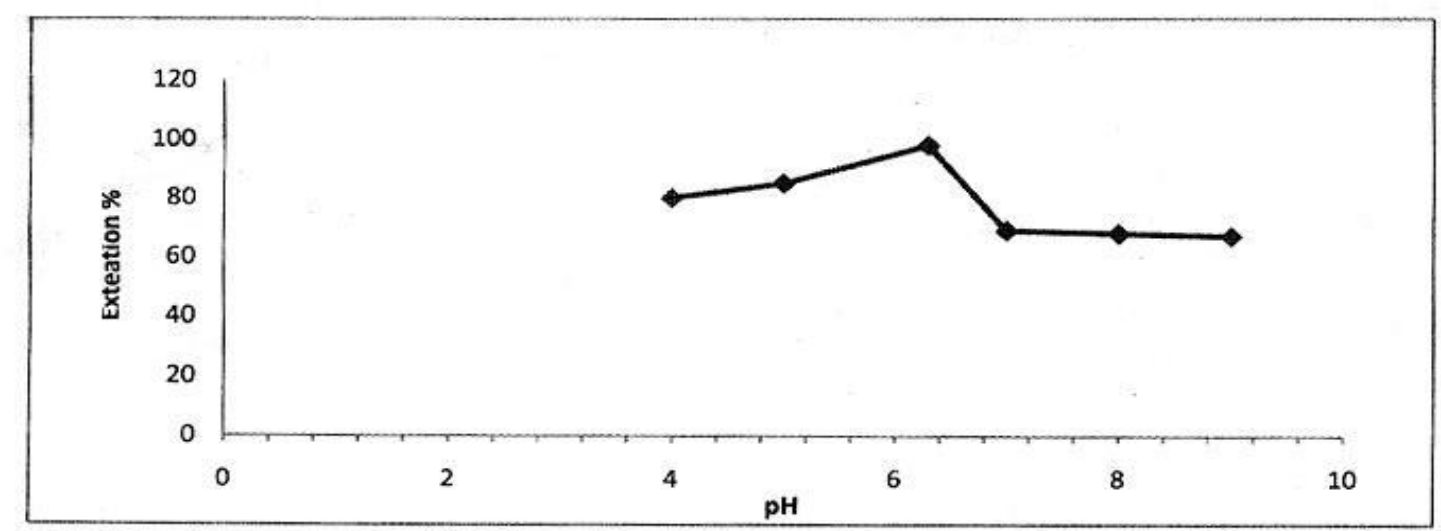

Fig ( 2) Extraction of $\mathrm{Cu}(\mathrm{II})$ as a Function of $\mathrm{pH}$ Choice of solvent

Various solvents dichloroethane, dichloromethane, chloroform, carbon tetra chloride and hexane are used for the extractuion of copper (II) dicylohexy 18 crown -6 complex to investigate the suitability of solvents (Fig3). It is found that the extraction of copper(11)complex is quantitative in dichloroethane. 


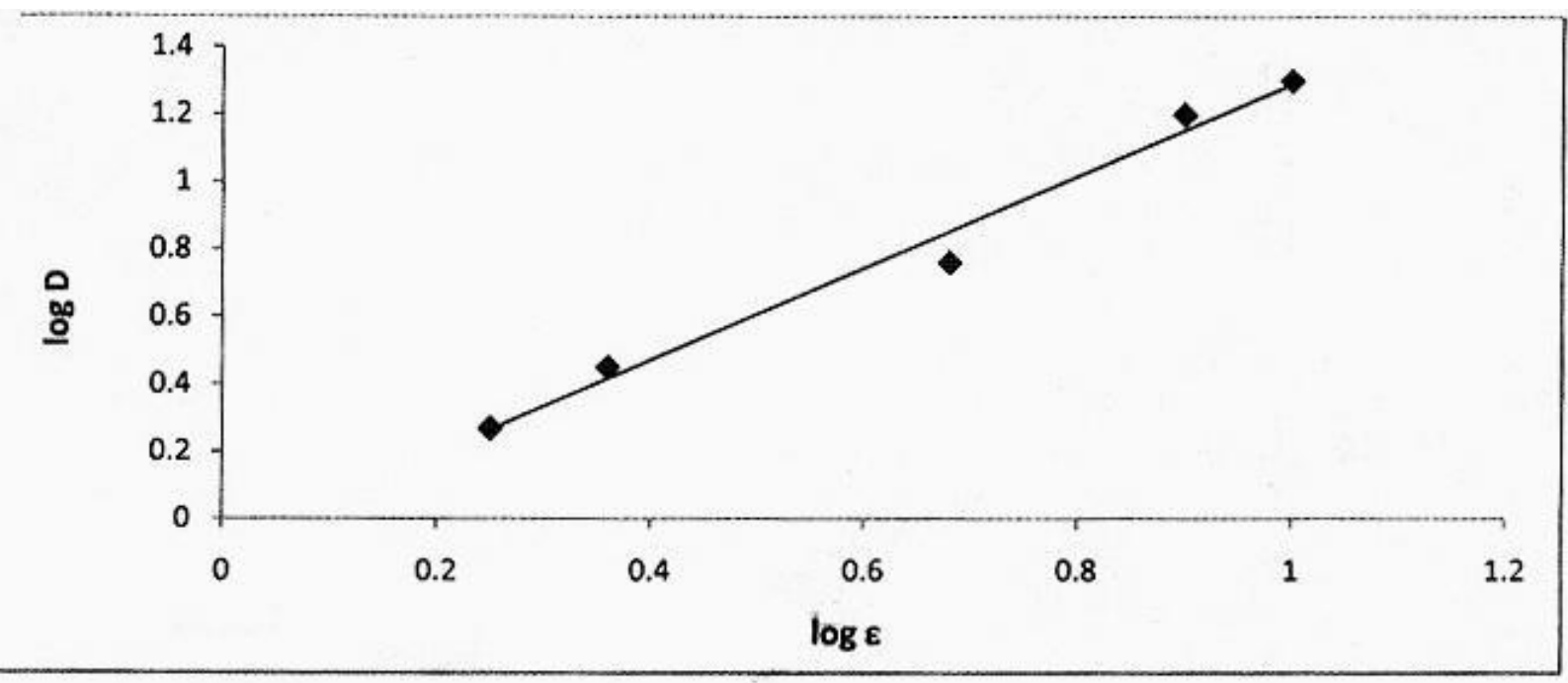

Fig (3) Effect of organic solvent on D distribution

A linear relationship has been observed between $\log \mathrm{D}$ and $\log \varepsilon$. As the solvent is varied.

The solvent can be arranged in the decreasing order of their extraction coefficients as dichloroethane $>$ dichloromethane $>$ chloroform $>$ carbon tetra chloride $>$ hexane.(Table 1).

Hence dichloroethane is used for further extraction studies as it gave better and fast phase separation

Table (1) Distribution percent values for extraction of copper by using DCH-18C-6 which are soluble in different Dielectric constant solvents.

\begin{tabular}{|l|l|l|l|}
\hline Solvent & $\begin{array}{l}\text { Dielectic } \\
\text { constant }(\varepsilon)\end{array}$ & $\log \varepsilon$ & $\log D^{*}$ \\
\hline Dichloroethane & 10.4 & 1.0 & 1.3 \\
\hline Dichloromethane & 8.1 & 0.9 & 1.2 \\
\hline Chloroform & 4.80 & 0.68 & 0.76 \\
\hline carbon tetra chloride & 2.3 & 0.36 & 0.45 \\
\hline Hexane & 1.8 & 0.25 & 0.27 \\
\hline
\end{tabular}

\section{*Distribution ratio .}

\section{effect of reagent volume}

Various volumes of $1 \times 10^{-3} \mathrm{M}$ reagent solution are added to the aqueous solution containing $40 \mu \mathrm{g}$ of copper (II) at $\mathrm{pH}(6.3)$.
The absorbance remained nearly constant when the volume of the reagent solution is $4 \mathrm{ml}$. 


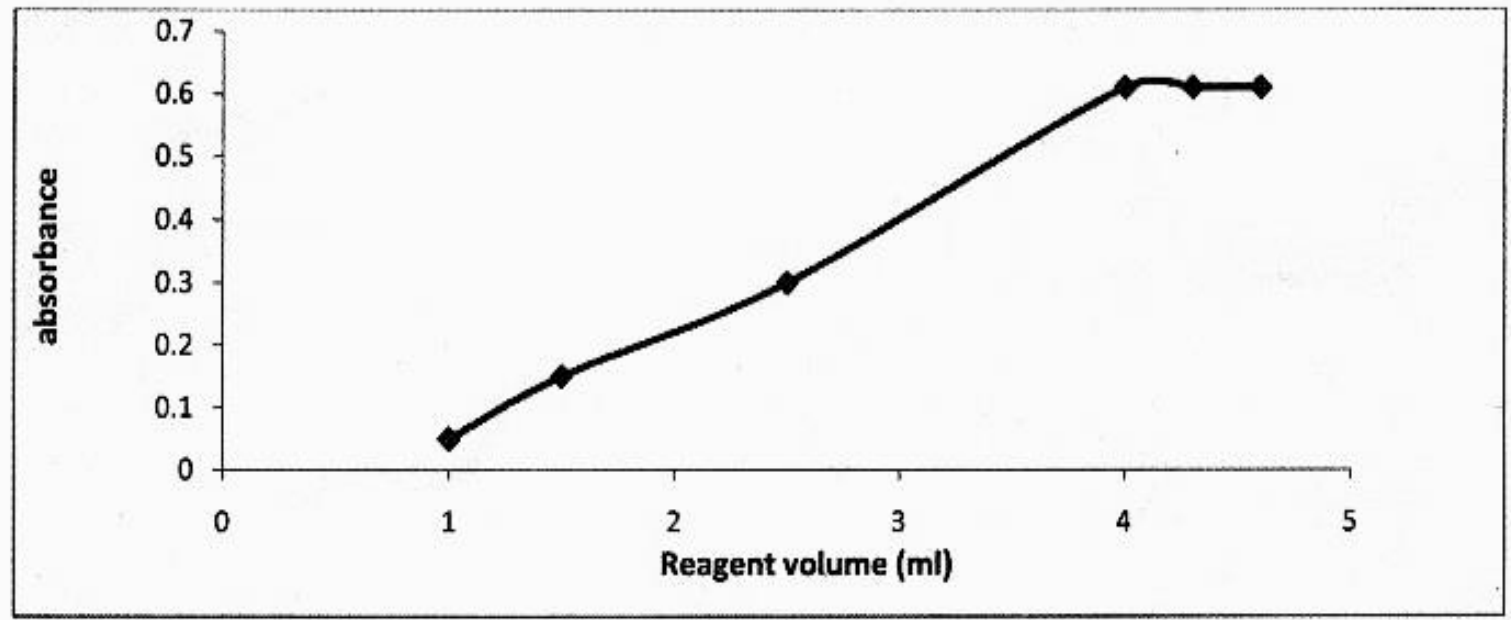

Fig (4) Effect reagent volume on the Extraction of $\mathrm{Cu}$ (II)

Therefore $4 \mathrm{ml}$ of $1 \times 10^{-3} M$ reagent was chosen as optimum.

Beer`s range dicyclohexyl -18 --crown-6 concentration, gives linear graph in conc. Range (5-45) $\mu \mathrm{g}$ of copper

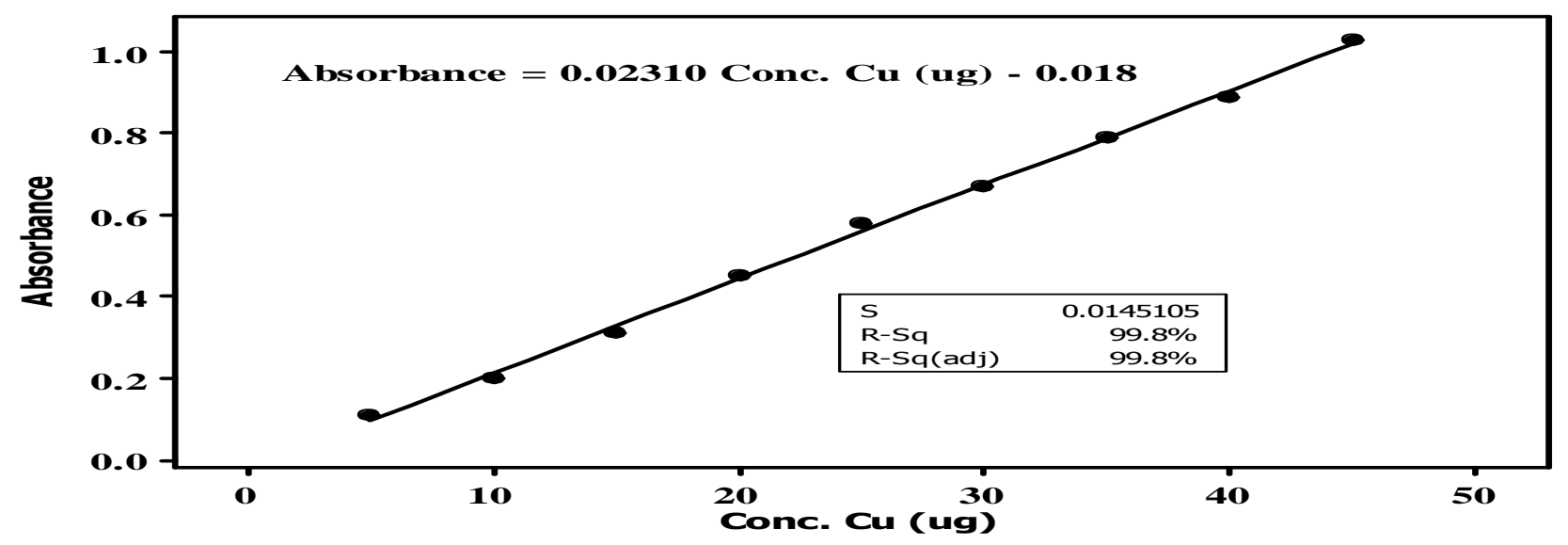

Fig (5) Calibration plot of $\mathrm{Cu}$ (II) DCH-18-Crowm-6 
Table (2) : Statistical treatment of calibration curve (figures of merit) for $\mathrm{Cu}$ (II)

\begin{tabular}{|l|l|}
\hline Parameter & Value \\
\hline$\lambda_{\max }(\mathrm{nm})$ & 469 \\
\hline Regression equation & $\mathrm{Y}=0.023 \mathrm{x}-0.018$ \\
\hline Correlation coefficient( $\mathrm{r})$ & 0.9989 \\
\hline Coefficient of determination $\left(\mathrm{R}^{2}\right)$ & $99.8 \%$ \\
\hline C.L. for the slope $\left(\mathrm{b} \pm \mathrm{ts}_{\mathrm{b}}\right)$ at $95 \%$ & $0.023 \pm 0.0123$ \\
\hline C.L. for the intercept $\left(\mathrm{a} \pm \mathrm{ts}_{\mathrm{b}}\right)$ at $95 \%$ & $-0.018 \pm 0.0131$ \\
\hline Concentration range $(\mu \mathrm{g})$ & $5-45$ \\
\hline Limit of Detection $(\mu \mathrm{g})$ & 1.89 \\
\hline Limit of Quantitation $(\mu \mathrm{g})$ & 6.31 \\
\hline Sandell's sensitivity $\left(\mu \mathrm{g} . \mathrm{cm}^{2} / 0.001 \mathrm{~A} . \mathrm{U}\right)$ & $4.6600 \times 10^{-5}$ \\
\hline Molar absorptivity $\left(\mathrm{L} \cdot \mathrm{mol}^{-1} . \mathrm{cm}^{-1}\right)$ & $1 \times 10^{4}$ \\
\hline Composition of complex $(\mathrm{M}: \mathrm{L})^{*}$ & $1: 2$ \\
\hline$(\mathrm{n}=5)$ RSD \% for Cu at $19.49 \mu \mathrm{g}$ & 2.1 \\
\hline
\end{tabular}

*obtained by slope ratio method

Stoichoimetry of the complex

The composition of extracted species has been determined by slope analysis method. It shows that the composition of $\mathrm{Cu}$ (II) $\mathrm{DCH}-18$ crown-6 complex. is $1: 2$.

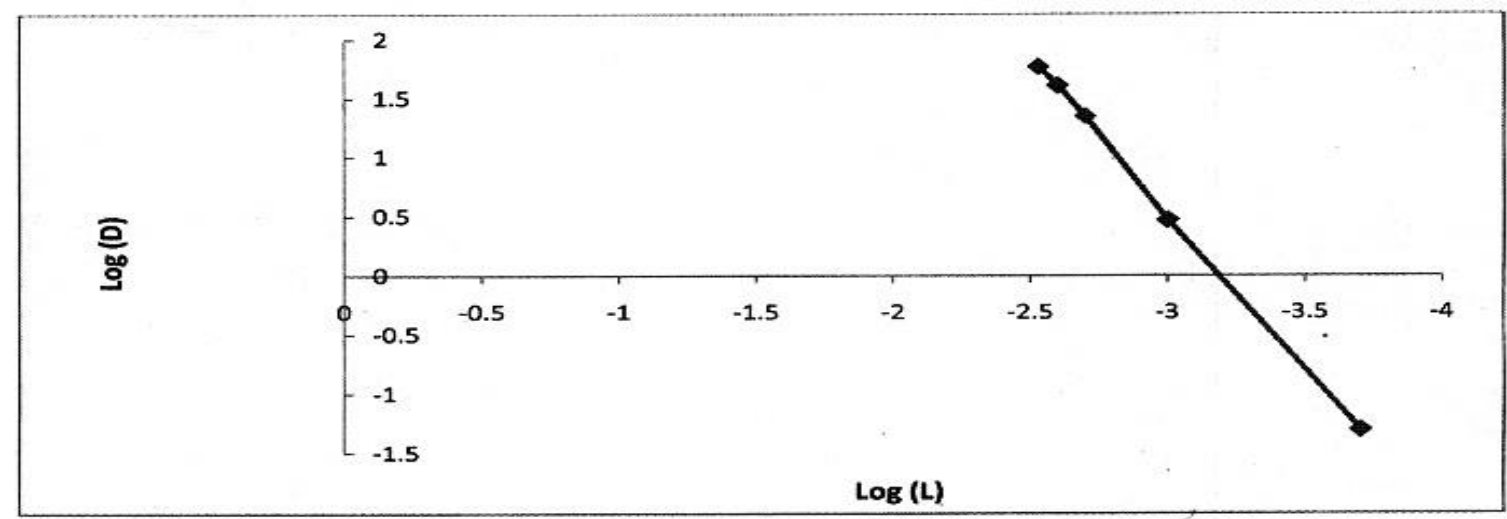

Fig( 6) Slope analysis method for $\mathrm{Cu}(\mathrm{II}) \mathrm{DCH}-18-\mathrm{Crown}-6$

Stability of complex

The study of stability of colour of $\mathrm{Cu} \quad$ (11)dicyclohexyl-18-crown-6 complex with respect to time shows that the absorbance due to extracted species is stable up to 30 hours, after which slight decrease in absorbance is observed.

\section{Effect of some cations and anions in Extraction}

The effect of the various ions were investigated in order to find limit of these ions in the extraction of $\mathrm{Cu}(11)$.Interferance was observed in the presence of ions at amounts $\mathrm{mol} / \mathrm{L}^{-1}$ (Table3). 
Table( 3) effect of divelent ions on extraction.

\begin{tabular}{|l|l|l|l|}
\hline Ion & Conc $\left(\mathrm{mg} \mathrm{ml}^{-1}\right.$ & $\mathrm{D}$ & $\mathrm{E} \%$ \\
\hline $\mathrm{Co}^{+2}$ & $1.2 \times 10^{-4}(15 \mu \mathrm{g})$ & 2 & $80 \%$ \\
\hline $\mathrm{Ni}^{+2}$ & $4.5 \times 10^{-4}(57 \mu \mathrm{g})$ & 21 & $97 \%$ \\
\hline $\mathrm{Mn}^{+2}$ & $5.4 \times 10^{-4}(68 \mu \mathrm{g})$ & 15 & $96 \%$ \\
\hline $\mathrm{Mg}^{+2}$ & $3.7 \times 10^{-4}(47 \mu \mathrm{g})$ & 20 & $97 \%$ \\
\hline $\mathrm{CIO}_{4}^{-2}$ & $4.4 \times 10^{-4}(55 \mu \mathrm{g})$ & N.E & - \\
\hline
\end{tabular}

E\% Percentage Extraction

N.E: No Extraction

\section{Conclusion:}

Reagent cyclohexyl-18-crown-6 provides a simple, rapid and accurate method for spectrophotometric determination of copper(11).It has advantages of high sensitivity selectivity and easy availability.

\section{References:}

1.Aswar.A.S and Joshi, M.D.2007. Solvent extrac. and spectro. determ. of Copper(11)with HMAINH, Indian J. Chem. Tec. 15(1): 79-81.

2.Parham, H. and Mobarakzadch M.2002. Solvent extrac. and determ. of trace- ,Talanta 58(2) : 281-287.

3.Taheri,K.,Chamsaz, M..Rounaghi, G.H.,Ansari, fard,M2009Study of Complex forma.- ,J.incl phen. Macro. Chem. 63(3) :43-52..

4.Lokhande,R.S.,Sonawane, R.P. and Chavan Utkarsha.2011. Develop. of method for extrac. And specro. determ. of $\mathrm{Cu}(11)$ with hydrazine-, Int.J.Chem.Sci.9(2) : 503-509.

5. Scheinberg,T.H.,Proc.1969 .Univ. Massouris 3rd Annual conference on Trace substances in Environ. Health 79.
6. Nason, A, and Neetrov,D.W.1963 . Plant Physiologe,3,Academic press, New York p210.

7.Nogy,L.G.,Tokok,G.Szokoyi,I. and Giber, J. 1928. ,Int. Conference of modern Trends in activation analysis Maryland, U.S.A.,411.

8 ..Lokhande,R.S. and Jayant,,A.S., 1999 Extraction . and spectro. determ. of Copper with 4- Chloro iso nitroso acetophenone semi carbazone, Asian J.Chem.11(4) : 1040.

9. Mandalik, P,R.,More ,B.M. and Answar A.S.2003. Synthesis, spectr. and antib. studies of oxo moly., indine J. Chem 42A(1), 106.

10. Prasad ,NBL,Reddy KH,and Reobly St.2006. Simult. first deriv. Spectro. determ. of Copper(11)and nickel(11) using 1-phenyl-, J .Indan Chem. Soc., 83(2) : 485.

11. Poman ,S.V. and Lokhande ,R.S.2001. Ext. and spectro. determ. of $\mathrm{Cu}$ with 4-Chloro iso nitroso acetophenone thio semi carbazone ,Asian J.Chem. 13 (1):1222. 
الاستخلاص المذيبي للنحاس بوساطه داي سايكلو هيكسيل -18-كراون-6وتعينه بتقنية المطيافيه الضوئيه

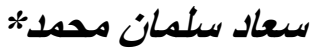

* جامعة بغداد /كلية العلوم للبنات /قسم الكيمياء

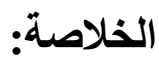

6م استخدام طريقه الاستخلاص بالمذيب لتعين النحاس في الوسط المائي بطريقه لونيه باستعمال الكاثنف

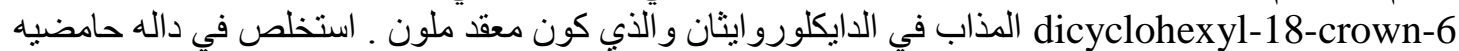

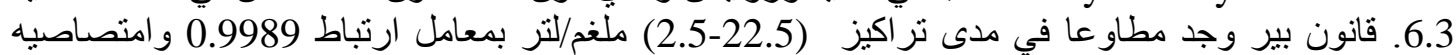

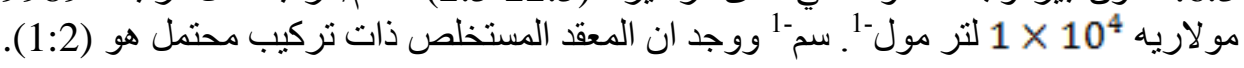

